Journal of Mathematics and Statistics 6 (3): 357-358, 2010

ISSN 1549-3644

(C) 2010 Science Publications

\title{
Edge Double-Critical Graphs
}

\author{
John J. Lattanzio \\ Department of Mathematics, Indiana University of Pennsylvania \\ Indiana, Pennsylvania 15705, USA
}

\begin{abstract}
Problem statement: The vertex double-critical conjecture that the only vertex doublecritical graph is the complete graph has remained unresolved for over forty years. The edge analogue of this conjecture has been proved. Approach: It was observed that if the chromatic number decreases by two upon the removal of a 2-matching, then the 2-matching comprises four vertices which determine an induced subgraph isomorphic to the complete graph on four vertices. This observation was generalized to t-matchings. Results: In this note, it has been shown that the only edge doublecritical graph is the complete graph. Conclusion/Recommendations: An alternate proof that the only edge double-critical graph is the complete graph has been obtained. Moreover, the result has been obtained independently.
\end{abstract}

Key words: Chromatic number, critical clique, k-matching

\section{INTRODUCTION}

The graphs considered in this study are finite, undirected and simple. For a given graph $\mathrm{G}$, the vertex and edge sets of $\mathrm{G}$ are denoted by $\mathrm{V}(\mathrm{G})$ and $\mathrm{E}(\mathrm{G})$, respectively. The order of $\mathrm{G}$, denoted by $n=|V(G)|$, is the cardinality of $\mathrm{V}(\mathrm{G})$. An r-clique is a complete subgraph of order $r$ and is denoted by $\mathrm{K}_{\mathrm{r}}$. A subset $\mathrm{M}$ of $\mathrm{E}(\mathrm{G})$ is said to be independent whenever no two edges in $M$ share a common vertex. In case $|\mathrm{M}|=\mathrm{k}$, the set $\mathrm{M}$ is called a k-matching. For a subset $X$ of $V(G)$, the subgraph of $\mathrm{G}$ induced by $\mathrm{X}$ is denoted by $\mathrm{G}[\mathrm{X}]$. All vertex colorings are proper, i.e., a partition of $V(G)$ into independent subsets of $V(G)$ called color classes. Lastly, $\chi(\mathrm{G})$ denotes the chromatic number of $\mathrm{G}$ and is the minimum cardinality of a partition of $V(G)$ determined by a proper vertex coloring of $\mathrm{G}$.

A graph $\mathrm{G}$ is said to be vertex double-critical provided $\chi(\mathrm{G}-\mathrm{v})=\chi(\mathrm{G})-2$ for every adjacent pair of vertices $u, v$. This definition arises out of its relation to the Erdos-Lovasz Tihany Conjecture. A special case of this conjecture is that the only vertex double-critical graph is the complete graph; it is often referred to as the Erdos-Lovasz double-critical conjecture. A brief discussion of the Erdos-Lovasz Tihany Conjecture and related results for quasi-line graphs are given in (Balogh et al., 2009). Stiebitz (1987) has shown that $\mathrm{K}_{5}$ is the only 5-chromatic vertex double-critical graph. To date, the Erdos-Lovasz double-critical conjecture remains open for k-chromatic graphs with $\mathrm{k} \geq 6$. In Theorem 6 of (Kawarabayashi et al., 2010), the edge analogue of the Erdos-Lovasz double-critical conjecture is proved. This note offers an independent proof of the edge analogue of the Erdos-Lovasz double-critical conjecture. Relations to FTTMs and the inertia tensor of a tetrahedron as defined in (Ahmad et al., 2010; Tonon, 2005), respectively are also being investigated.

Edge double-critical graphs: It is now shown that $\mathrm{K}_{\mathrm{n}}$ is the only edge double-critical graph. First, some notational conventions and a required definition are given. Let $M_{t}=\left\{e_{1}, e_{2}, \ldots, e_{t}\right\}$ be a set of $t$ edges in $E(G)$ and set $e_{i}=u_{i} v_{i}$ for $i=1,2, \ldots$, t. Next, define $M_{t}{ }^{*}$ $=\left\{\mathrm{u}_{1}, \mathrm{v}_{1}\right\} \cup\left\{\mathrm{u}_{2}, \mathrm{v}_{2}\right\} \cup \cdots \cup\left\{\mathrm{u}_{\mathrm{t}}, \mathrm{v}_{\mathrm{t}}\right\}$. Clearly, $\mathrm{M}_{\mathrm{t}}$ is a $\mathrm{t}-$ matching when $\left|\mathrm{M}_{\mathrm{t}}\right|=2 \mathrm{t}$.

Definition 1: Let $G$ be a graph which contains 2matchings. Then $\mathrm{G}$ is called edge double-critical whenever $\chi\left(\mathrm{G}-\mathrm{M}_{2}\right)=\chi(\mathrm{G})-2$ for every 2-matching $\mathrm{M}_{2}$.

Necessarily, an edge double-critical graph is connected. An important observation is given in the following lemma.

Lemma 1: Let $M_{2}=\left\{e_{1}, e_{2}\right\}$ be a 2-matching such that $\chi\left(\mathrm{G}-\mathrm{M}_{2}\right)=\chi(\mathrm{G})-2$. Then $\mathrm{G}\left[\mathrm{M}_{2}{ }^{*}\right] \cong \mathrm{K}_{4}$.

Proof: Set $\mathrm{k}=\chi(\mathrm{G})$ and let $\mathrm{e}_{\mathrm{i}}=\mathrm{u}_{\mathrm{i}} \mathrm{v}_{\mathrm{i}}$ for $\mathrm{i}=1,2$. Consider any (k-2)-coloring of G-M $\mathrm{M}_{2}$, the colors being from among $\left\{c_{1}, c_{2}, \ldots, c_{k-2}\right\}$. Then $u_{1}$ and $v_{1}$ must be colored the same since otherwise there would exist a $(\mathrm{k}-$ 2)-coloring of $\mathrm{G}-\mathrm{e}_{2}$. A similar argument shows that $\mathrm{u}_{2}$ and $\mathrm{v}_{2}$ must be colored the same, necessarily using a different color from that used for $\mathrm{u}_{1}$ and $\mathrm{v}_{1}$. Next, 
observe that $\mathrm{u}_{1} \mathrm{u}_{2} \in \mathrm{E}\left(\mathrm{G}-\mathrm{M}_{2}\right)$. Else, both $\mathrm{u}_{1}$ and $\mathrm{u}_{2}$ could be recolored using color $\mathrm{c}_{\mathrm{k}-1}$. But this would allow $\mathrm{e}_{1}$ and $\mathrm{e}_{2}$ to be added back to $\mathrm{G}-\mathrm{M}_{2}$ resulting in a coloring of $\mathrm{G}$ using fewer than $\mathrm{k}$ colors. A similar argument shows that $\mathrm{u}_{1} \mathrm{v}_{2}, \mathrm{v}_{1} \mathrm{u}_{2}, \mathrm{v}_{1} \mathrm{v}_{2} \in \mathrm{E}\left(\mathrm{G}-\mathrm{M}_{2}\right)$. Consequently, $\mathrm{G}\left[\mathrm{M}_{2}^{*}\right] \cong \mathrm{K}_{4}$.

Theorem 1: Let $\mathrm{t} \geq 1$. If $\chi\left(\mathrm{G}-\mathrm{M}_{\mathrm{t}}\right)=\chi(\mathrm{G})$ - $\mathrm{t}$, then $\mathrm{M}_{\mathrm{t}}$ is $\mathrm{a}$ t-matching of $\mathrm{G}$. Moreover, $\mathrm{G}\left[\mathrm{M}_{\mathrm{t}}^{*}\right] \cong \mathrm{K}_{2 \mathrm{t}}$.

Proof: Let $\mathrm{k}=\chi(\mathrm{G})$. The result is trivial for $\mathrm{t}=1$. Let $\mathrm{t}$ $\geq 2$ and consider a subset $\mathrm{M}_{\mathrm{t}}$ of $\mathrm{E}(\mathrm{G})$ such that $\chi\left(\mathrm{G}-\mathrm{M}_{\mathrm{t}}\right)$ $=\mathrm{k}$-t. Because $\left|\mathrm{M}_{\mathrm{t}}\right|=\mathrm{t}$, it follows that $\mathrm{M}_{\mathrm{t}}$ is a $\mathrm{t}$-matching as incident edges can decrease the chromatic number of a graph by at most one upon their removal. Observe now that for all pairs $i, j$ with $i \neq j, \chi\left(G-e_{i}-e_{j}\right)=k-2$. By setting $\mathrm{M}_{2}(\mathrm{i}, \mathrm{j})=\left\{\mathrm{e}_{\mathrm{i}}, \mathrm{e}_{\mathrm{j}}\right\}$ and applying Lemma 1 , $\mathrm{G}\left[\mathrm{M}_{2}{ }^{*}(\mathrm{i}, \mathrm{j})\right] \cong \mathrm{K}_{4}$. Hence, $\mathrm{G}\left[\mathrm{M}_{\mathrm{t}}^{*}\right] \cong \mathrm{K}_{2 \mathrm{t}}$.

Proposition 1: Every t-matching in $\mathrm{K}_{2 \mathrm{t}}$ is critical.

Proof: The proof is by induction on $\mathrm{t}$. For $\mathrm{t}=1$, the result is trivial. Since $\chi\left(\mathrm{K}_{4}-\mathrm{M}\right)=\chi\left(\mathrm{C}_{4}\right)=2$ for every 2 matching $\mathrm{M}$ of $\mathrm{K}_{4}$, Proposition 1 holds for $\mathrm{t}=2$. Now, inductively assume that Proposition 1 holds for $t=1,2$, $\ldots, \mathrm{t}^{\prime}-1$. Let $\mathrm{M}_{\mathrm{t}^{\prime}}$ be any $\mathrm{t}^{\prime}$-matching in $\mathrm{K}_{2 \mathrm{t}^{\prime}}$. Notice that $\mathrm{K}_{2 \mathrm{t}^{\prime}}$ can be written as $\mathrm{K}_{2 \mathrm{t}^{\prime}}=\mathrm{K}_{2}+\mathrm{K}_{2\left(\mathrm{t}^{\prime}-1\right)}$. Moreover, it can be assumed, without loss of generality, that the single edge in the $K_{2}$ term is in the $t^{\prime}$-matching $M_{t^{\prime}}$. Consequently, $\mathbf{M}_{\mathrm{t}^{\prime}}$ can be written as $\mathbf{M}_{\mathrm{t}^{\prime}}=\mathrm{M}_{1} \cup \mathrm{M}_{\mathrm{t}^{\prime}-1}$, where $M_{1}$ is the 1-matching in the $K_{2}$ term and $M_{t^{\prime}-1}$ is a $\left(\mathrm{t}^{\prime}-1\right)$-matching in the $\mathrm{K}_{2\left(\mathrm{t}^{\prime}-1\right)}$ term. By the inductive hypothesis, $\chi\left(\mathrm{K}_{2\left(\mathrm{t}^{\prime}-1\right)}-\mathrm{M}_{\mathrm{t}^{\prime}-1}\right)=\mathrm{t}^{\prime}-1$. Therefore:

$\mathrm{K}_{2 \mathrm{t}^{\prime}}-\mathrm{M}_{\mathrm{t}^{\prime}}=\left(\mathrm{K}_{2}+\mathrm{K}_{2\left(\mathrm{t}^{\prime}-1\right)}\right)-\left(\mathrm{M}_{1} \cup \mathrm{M}_{\mathrm{t}^{\prime}-1}\right)=\left(\begin{array}{ll}\mathrm{K}_{2} & -\mathrm{M}_{2}\end{array}\right)+$ $\left(\mathrm{K}_{2\left(\mathrm{t}^{\prime}-1\right)}-\mathrm{M}_{\mathrm{t}^{\prime}-1}\right)=\mathrm{E}_{2}+\left(\mathrm{K}_{2\left(\mathrm{t}^{\prime}-1\right)}-\mathrm{M}_{\mathrm{t}^{\prime}-1}\right)$

Hence, $\chi\left(\mathrm{K}_{2 \mathrm{t}^{\prime}}-\mathrm{M}_{\mathrm{t}^{\prime}}\right)=1+\left(\mathrm{t}^{\prime}-1\right)=\mathrm{t}^{\prime}$.

Corollary 1: Every matching in $K_{n}, n \geq 2$, is critical.

Lemma 1 and Corollary 1 together set the stage for the main result of this note.

Theorem 2: $\mathrm{G}$ is edge double-critical if and only if $\mathrm{G} \cong$ $\mathrm{K}_{\mathrm{n}}$, provided $\mathrm{n} \geq 4$.

Proof: If $\mathrm{G} \cong \mathrm{K}_{\mathrm{n}}$, where $\mathrm{n} \geq 4$, then by Corollary 1 , every 2-matching in $K_{n}$ is critical. Thus, $G$ is edge double-critical. Conversely, let $\mathrm{G}$ by a connected, edge double-critical graph. Take any $\mathrm{u}, \mathrm{v} \in \mathrm{V}(\mathrm{G})$ and suppose to the contrary that $u v \notin E(G)$. Then $N(u)=N(v)=$ $\left\{\mathrm{w}_{\mathrm{u}, \mathrm{v}}\right\}$ for some vertex $\mathrm{w}_{\mathrm{u}, \mathrm{v}} \in \mathrm{V}(\mathrm{G})$. Otherwise, because $\mathrm{G}$ is connected, it would follow that $\mathrm{u}, \mathrm{v} \in \mathrm{M}_{2}{ }^{*}$ for some 2-matching $\mathrm{M}_{2}$. Since $\mathrm{G}$ is edge doublecritical, $\mathrm{G}\left[\mathrm{M}_{2}{ }^{*}\right] \cong \mathrm{K}_{4}$ by Lemma 1 . This implies that uv $\in \mathrm{E}(\mathrm{G})$, contrary to our supposition. Next, observe that $\mathrm{N}(\mathrm{z})=\left\{\mathrm{w}_{\mathrm{u}, \mathrm{v}}\right\}$ for every vertex $\mathrm{z} \neq \mathrm{w}_{\mathrm{u}, \mathrm{v}}$. Else, by using exactly the same argument as above, we would be forced to conclude that $\mathrm{z} \in \mathrm{N}(\mathrm{u})=\left\{\mathrm{w}_{\mathrm{u}, \mathrm{v}}\right\}$, which is clearly not possible by the choice of $\mathrm{z}$. The above argument leads to the conclusion that $G$ is a star. But such a graph is known not to be edge double-critical because of the absence of 2-matchings in any star. Hence, $u v \in E(G)$ so that $G \cong K_{n}$.

\section{REFERENCES}

Ahmad, T., S.S. Jamian and J. Talib, 2010. Generalized finite sequence of fuzzy topographic topological mapping. J. Math. Stat., 6: 151-156. http://www.scipub.org/fulltext/jms2/jms262151156.pdf

Balogh, J., A.V. Kostochka, N. Prince and M. Stiebitz, 2009. The Erdos-Lovasz Tihany conjecture for quasi-line graphs. Discr. Math., 309: 3985-3991. DOI: 10.1016/j.disc.2008.11.016

Kawarabayashi, K.I., A.S. Pedersen and B. Toft, 2010. Double-critical graphs and complete minors. Elect. J. Combin., 17: 1-27. http://www.combinatorics.org/Volume_17/PDF/v1 7i1r87.pdf

Stiebitz, M., 1987. $\mathrm{K}_{5}$ is the only double-critical 5chromatic graph. Discr. Math., 64: 91-93. DOI: 10.1016/0012-365X(87)90242-1

Tonon, F., 2005. Explicit exact formulas for the 3-D tetrahedron inertia tensor in terms of its vertex coordinates. J. Math. Stat., 1: 8-11. http://www.scipub.org/fulltext/jms2/jms211811.pdf 